\title{
I AM NOT SELLING ANYTHING: 29 EXPERIMENTS IN TELEPHONE INTRODUCTIONS
}

\author{
Edith D. de Leeum and Foop F. Hox
}

Telephone surveys have become more and more popular in the last thirty years, reaching their zenith in the I990s. At the end of the twentieth century, telephone surveys were the major mode of data collection for sample surveys in North America and Western Europe (Nathan, 200I). The main advantages, compared to face-to-face interviews, are lower costs and stricter interviewer control. In addition, extensive research has improved telephone survey methods considerably (e.g., Groves, Biemer et al., I988), and telephone surveys can produce high quality data (Leeuw, I992; Leeuw \& Zouwen, I988).

In the new millennium, telephone interviewers are faced with new problems that threaten the validity of the method. The growing number of unsolicited calls (e.g., tell-sell, telemarketing, polls) may lessen the willingness to cooperate. The American Statistical Association ( I999) mentions the near saturation calling conducted by telemarketers as one of the causes of declining survey cooperation rates. An indication of the growing irritation with unsolicited calls is that millions of Americans immediately registered when the Federal 'do-not-call' registry started in June 2003 (Schulman, 2003; Robinson, 2003). Although not yet at the high American level, unsolicited phone calls are becoming a nuisance factor in Europe too. Recent studies in the Netherlands showed that each Dutch adult receives five uninvited phone calls a year on average. Although some sub-conditions will receive considerably more calls, depending on age, profession, and status, overall a Dutch household will answer eleven unsolicited calls a year on average (Steenis, I998).

Therefore, it is not surprising that there is a growing negative attitude towards market research in the Netherlands. When asked about market research, 28 percent of the respondents say that they are asked to cooperate far too often. Even more worrisome is that 22 percent are convinced that market research is selling under the guise of research (Brennecke, I998). This will influence the interpretation of the intent of a call; in psychological terms it will change the cognitive script that guides the reactions to uninvited calls. More often potential respondents will react to uninvited telephone calls, using the 'they want to sell me something'-script, because experience taught them to expect a sales-pitch and not a serious and legitimate survey.

Telephone interviewers are more limited than face-to-face interviewers in the tools they have at their disposal to correct this erroneous script and to convince a potential respondent that this is a legitimate survey. Telephone interviewers have fewer opportunities, fewer

With sincere thanks to Janny Lok and Rob van Leeuwen, former directors of 'Uw Mening Telt' and initiators of this project, for their dedicated and enthusiastic support. Many thanks are also due to the project managers at the research agencies who collected the data. We also thank Karen Goldenberg and Mick Couper for their suggestions, and two anonymous reviewers and Wolfgang Donsbach for their constructive comments.

The note was first submitted to IfPOR August 29, 2002. The final version was received February 9, 2004. 
means and less time to convince reluctant respondents than face-to-face interviewers. Telephone interviewers cannot take advantage of visual cues and nonverbal communication to evaluate the situation and persuade a potential respondent (for successful face-toface strategies, see Snijkers, Hox, \& Leeuw, I999; Campanelli, Sturgis, \& Purdon, 1997). In their introduction, telephone interviewers can only use auditive and paralinguistic communication to convey their message. They cannot show identity cards, or use other visual cues. In other words, it all depends on what is being said in the introduction and how it is said. In addition, since a telephone interviewer has far less time than a face-toface interviewer, the message should be very short to prevent break-offs (for telephone interviewer strategies, see Hox, Leeuw, \& Snijkers, 1998). Typically, in face-to-face interviews the initial interaction is completed within two to five minutes, while in telephone interviews the majority of the decisions to cooperate or refuse are made within one minute (Groves, I992). Finally, when random digit dialing is used, this sampling method precludes the use of advance letters to introduce and legitimize the survey (Groves \& Couper, I998; Nathan, 200I; Pondman, 1998).

One of the few tools a telephone interviewer has available to establish legitimacy at the outset is simply stating, 'I am not selling anything.' Although initial experiments in the USA were positive (Gonzenbach \& Jablonski, 1993) and some research firms both in the USA and Europe already use a non-solicitation statement in the introduction, others refrain from it because they are afraid to alert respondents (Goold, I997). To provide empirical data, we designed a controlled large-scale experiment and tested the effect of the 'I am not selling'-message on the response in a series of 29 split ballot experiments in the Netherlands.

\section{METHOD}

\section{Data Collection}

We wanted to test a 'not selling'-introduction in standard random sampling household telephone surveys. To establish the legitimacy of the survey at the outset we used the following introduction: 'Good-evening/morning/afternoon, this is ... from... We are conducting a survey on...We are not selling anything. To ensure we get a scientific sample, I would like to speak to... (next birthday-selection or other selection method).' In this introduction the message 'we are not selling anything' is reinforced by the words 'scientific sample', to convey that a serious, legitimate survey is being conducted. For those surveys in which no respondent selection at all was used, the introduction was simply 'Good-evening/morning/afternoon, this is...from... We are conducting a survey on ... We are not selling anything.'

In order to test the 'not selling'-introduction a series of 29 split-run experiments were conducted at different periods (spring, summer, fall, winter) in 1999. These experiments were coordinated by the Dutch public information center 'Your Opinion Counts' ( $\mathrm{Uw}_{w}$ Mening Telt), ensuring that individual data of research institutes would not be disclosed. Data were collected at ten Dutch market research firms who are all members of the Netherlands Association for Market Research Companies. All firms agreed to conduct a split ballot experiment, using the experimental introduction in a random half of their 
sample, and their standard introduction (without 'not selling') in the other half. During the fieldwork, a senior researcher, responsible for that particular survey, filled in a questionnaire on topic and saliency of the survey and on fieldwork procedures used (e.g., timing of calls, maximum number of attempts, respondent selection).

All 29 experiments followed the same procedure: 'cold' calling for household surveys. This implies that only new samples were contacted, no advance letters were used, and no incentives were used. All firms always used a short scripted text in their standard introduction. The topics of the surveys varied, covering the normal range of market and opinion research. The populations investigated also covered the usual range from general population to specific conditions. In total, the results are based on I0 I,625 contacted, that is, the total number of people the interviewers reached and spoke to over the phone.

\section{Analysis}

For both the experimental condition (not selling) and the control condition (standard introduction) the following figures were registered for this study: the total number called minus the number of knomn ineligibles (e.g., fax, business number), the number of completed interviews, the number of partial interviews, the number of break-offs, the number of refusals, the number of non-contacts, and the number of other non-interviews (e.g., physically unable, language problems). Because the number of partial interviews was very small, we counted a partial interview as break-off.

Unit nonresponse is the failure to obtain any measurement on a sample unit (Dillman, Eltinge, Groves, \& Little, 2002). There are several indices for (non)response, each emphasizing a different source of nonresponse (Smith, 2002). From a practical point of view the response rate is of interest. The response rate is the number of completed interviews divided by the number of eligible reporting units in the sample. This figure is most often used in presentations, reports, articles, and papers. However, to evaluate the effectiveness of the 'not selling' argument, it is better to focus on the cooperation rate, where the number of completed interviews is divided by the total number of contacted known eligibles, instead of the number of known eligible units. After all, to evaluate the effectiveness of an argument, one should concentrate on the cases that are subjected to the argument in the introduction: the contacts.

We computed for both the experimental and control groups the following indices (see American Association for Public Opinion Research [AAPOR], I998, on standard definitions for the precise definitions): response rate $\left(\mathrm{RR}_{\mathrm{I}}\right.$, or minimum response rate, AAPOR, I998), cooperation rate (COOPI, or minimum cooperation rate, AAPOR, I998), contact rate, that is the proportion of all cases in which some responsible household member was reached (AAPOR, I998), and refusal rate. The refusal rate was calculated as proportion of refusals based on the total of eligible units contacted. In addition, we calculated an other-non-interview rate, indicating nonresponse for other, miscellaneous, reasons and break-off rate, an index for partial interviews caused by disconnection initiated by the respondent during the interview, in a manner similar to the refusal rate (AAPOR, I998). It should be noted that in each case we computed the most conservative estimate, therefore partial interviews were not counted as interviews. Also only known ineligible 
cases were counted as ineligible and no estimate of the proportion of ineligibles was made (cf. AAPOR, i 998, p. i 8).

To assess the global effectiveness we performed paired sample $t$-tests between the estimates for the experimental (no selling) and control (standard introduction) conditions. As the same agencies used both the non-solicitation and the standard introduction, the observations are not independent and a paired sample $t$-test is advised rather than the independent sample $t$-test. For the follow-up analyses, we used logistic regression with cooperation rate as dependent variable (Tabachnick \& Fidell, 200I). The goal of these follow-up analyses was to detect possible interactions with background variables, such as saliency of topic, and type of population. In other words, the goal was to investigate for which type of survey the 'not selling' argument is most effective (Hox \& Leeuw, 2002). Adding the factor 'agency' to the logistic regression equation controlled the dependency among the ten agencies.

\section{RESULTS}

\section{EFFECTIVENESS OF INTRODUCTION}

First of all, we tested whether there was any difference between the experimental ('not selling') and control (standard introduction) conditions in contact rate. There was no statistically significant difference between the two conditions $\left(p=.5^{6}\right)$; in both conditions the mean contact rate was 83 percent. In other words, the randomization in the split run experiments was successful.

In the next step we compared the experimental ('not selling') and control (standard introduction) conditions on response rate, cooperation rate, refusal rate, break-off rate and other-non-interview rate. There was a significant difference for the response rate, the cooperation rate, and the refusal rate. There was no significant difference for the other-non-interview rate (Table I).

There is a statistically significant improvement of response in the 'not selling' condition. The increase in response was 2 percentage points on average. This improvement was

\section{Table I Paired sample $t$-test}

\begin{tabular}{|c|c|c|c|c|c|}
\hline & \multicolumn{2}{|c|}{ 'Not selling'-introduction } & \multicolumn{2}{|c|}{ Standard introduction } & \multirow[t]{2}{*}{$p$} \\
\hline & Mean & $S D$ & Mean & $S D$ & \\
\hline Response rate & 0.262 & 0.12 & 0.246 & O.I I & .00 \\
\hline Cooperation rate & 0.309 & 0.12 & 0.289 & 0.12 & .00 \\
\hline Refusal rate & 0.579 & O.I3 & 0.603 & 0.12 & .00 \\
\hline Break-off rate & 0.013 & 0.02 & 0.015 & 0.03 & $.4 \mathrm{I}$ \\
\hline Other-non-interview & 0.096 & 0.10 & 0.089 & 0.09 & .39 \\
\hline
\end{tabular}

Note: Response rate (RRI according to AAPOR standard definitions) was based on the number of eligibles, while the other four indices were calculated with the number of contacted in the denominator. Cooperation rate is COOP I (AAPOR, I998).

$p$-value of $t$-test for five response indices. $N=29$ experiments. The analysis was based on ror, 625 contacted persons across 29 experiments, taking the multilevel structure into account (Hox, 2002). 
mainly caused by a lower number of refusals in the 'not selling' condition. Although the number of break-offs was also less, this difference was very small and did not reach statistical significance.

Summing up: on average, across all topics and research firms, adding the 'not selling' argument to the introduction is successful and increases the response in telephone interviews by 2 percentage points.

\section{Influence of Survey Characteristics on the Gain in Response}

The decision to respond depends on many factors; besides the interviewer's introduction other survey characteristics play a role (Groves \& Couper, I998; Leeuw, I999; Leeuw \& Heer, 2002). Such survey characteristics may interact with the efficacy of the 'not selling' argument. For instance, when the topic is very salient for the respondent, the 'not selling' argument may have far less influence than with a non-salient topic. In some studies in this experiment, it was possible to mention the sponsor (e.g., university, European Union) and establish legitimacy in this way; theoretically these studies did not need the 'not selling' argument (cf. Pinkleton, Reagan, Aaronson, \& Ramo, I994). Also, the research firms themselves differ in 'image' with the general public; some are well known from election polls and opinion research for the media (newspapers, television); others do not have this advantage.

To investigate these effects, all studies were coded by two independent coders on saliency ( $\mathrm{I}=$ not salient $, \ldots, 4=$ very salient indeed), on whether or not an official sponsor could be identified, and on type of population investigated. The coders also coded the number of words in the introduction before the actual 'not selling' argument was given. One should remember that each research firm in this experiment placed the "not selling' argument in their usual standard introduction. Some agencies used a more elaborate or longer introduction than others. This enables us to investigate the hypothesis that the 'not selling'argument is more effective if it is used as quickly as possible in the introduction.

It is often argued that some knowledge about the survey-burden may influence interviewer behavior. For instance, when an interview is long or has difficult questions, interviewers may be more reluctant or hesitant in their introduction (Groves \& Couper, I998, p. 289). We asked the senior researcher responsible for each survey to fill in a short questionnaire with background information on the survey, including average length of interview in minutes, number of open and closed questions, cognitive burden on respondent ( $\mathrm{I}=$ very simple questions, $\ldots, 5=$ very difficult questions). This enabled us to investigate the effect of expected interview burden.

We performed logistic regression analysis with cooperation rate as dependent variable. In the first step we only investigated main effects; the following variables showed a significant $(p<.05)$ result. Overall cooperation is influenced by saliency of topic, type of population (general vs. special), and local vs. nationwide study. Highly salient topics result in a higher response; when a special population (e.g., members of an organization) is interviewed, this also results in a higher response. In contrast, a nationwide study results in a lower response than a local study. These are all factors that depend on the research question itself and cannot be changed by a researcher. 
In addition, we found that the duration of the interview did influence response, but that cognitive burden (type of question, difficulty) did not. The effect of expected length of interview may be caused by differences in interviewer behavior; when interviewers know that an interview will take some time, they can—subconsciously—be less assured and more hesitant in their introduction. It can also be an effect of initial questions of the potential respondent. 'How long does it take' is one of the most commonly asked questions during the introductory 'spiel'. Potential respondents who pose this question will of course react to the answer. Unfortunately we do not have tape recordings of the introductions available to check this assumption.

In addition, there is a significant 'agency' effect; some agencies do better than others. But for all agencies, the experimental 'not selling' introduction did improve respondents' cooperation significantly.

In the next step, we investigated if the experimental introduction worked better in certain situations. In other words, we investigated the interaction of the variable experimental condition with background variables such as saliency, type of population, respondent selection. Again we used $p<.05$. Furthermore, we were interested in whether the place of the non-solicitation argument influenced the effectiveness. In telephone introductions, the interviewer has only a very short time to convey a message and convince a respondent; we therefore expect that the earlier the non-solicitation argument is presented the better it will work. Place of argument was measured as the length, that is the number of words, of the introduction before the 'not selling' argument

There was indeed a strong and significant interaction with the placement of the 'not selling' argument in the introduction. The argument worked best when it was given right at the start of the introduction. However, there were no significant interactions with type of population or respondent selection. The 'not selling' argument works equally well for the general population as for special groups, and when further respondent selection (e.g., next birthday method) was used. Finally, we did find a significant interaction with

\section{TABLE 2 Logistic regression on cooperation rate}

\begin{tabular}{lccc}
\hline & $b$ & $S E$ & $p$ \\
\hline Experimental condition &. $\mathrm{I} 3$ & .04 & $<$. OI \\
Saliency of survey topic & .42 & .03 & $<$. OI \\
Special population & $\mathrm{I} . \mathrm{I} 3$ & .05 & $<.0 \mathrm{I}$ \\
Nationwide sample & -.49 & .05 & $<.0 \mathrm{I}$ \\
Duration of interview & -.04 & .003 & $<.0 \mathrm{I}$ \\
Length of introduction before 'not selling' information & .00 & $.0 \mathrm{I}$ & .65 (n.s.) \\
Experimental condition * Saliency of topic & .08 & .03 & $.0 \mathrm{I}$ \\
Experimental condition* Length of introduction & -.003 & $.00 \mathrm{I}$ & $<.0 \mathrm{I}$ \\
Agencies & $\mathrm{chi}^{2}(9)=2 \mathrm{I} 32.2$ & $<.0 \mathrm{I}$ \\
\hline
\end{tabular}

Note: Cooperation rate was conservatively calculated as COOPI or minimum cooperation rate (AAPOR, I998). The significance of the categorical variable 'agencies' was tested with a likelihood-ratio test. Nonsignificant explanatory variables are not included. The exception is 'length of introduction'. The interaction experimental condition*length of introduction is significant, and interactions should always be interpreted with the direct effects of the variables that make up the interaction as a system (Jaccard, Turrisi, \& Wan, I990). Therefore the nonsignificant direct effect of 'length of introduction' is included in the regression. 
saliency, which indicates that the experimental introduction worked better with more salient topics. The non-solicitation argument seems more successful with more salient topics (e.g., European Community, health), and has less effect with the less salient (e.g., usage or buying of certain food products).

\section{CONCLUSIONS AND DISCUSSION}

Adding the message 'I am not selling anything' to the introduction does reduce refusals. There was a significant interaction with placement in the introduction: the 'not selling' argument works best when given right at the start of the introduction. A non-solicitation statement at the beginning of the introduction provides interviewers with a simple and effective tool to reduce nonresponse. People often refuse immediately after the announcement of the interviewer. For instance, when analyzing telephone introductions and the verbal interactions between interviewers and potential respondents, Maynard and Schaeffer (I997) found clear evidence that refusals occur very early in the opening of the phone call. Our finding provides empirical evidence that non-solicitation statements placed early in the introduction sequence work best to counteract this phenomenon.

Strictly speaking, the experimental condition contained two manipulations: 'not selling anything', and, in the case of further respondent selection on the phone, the words 'scientific sample.' In half of the cases ( 5 experiments), the interviewer had to select a respondent within the household (next birthday method) and used the words 'scientific sample' in the selection procedure. We found that there was no significant interaction between the experimental condition and respondent selection (see also above). Further control analyses, using paired sample $t$-tests separately for the experiments with random respondent selection, and thus with the words 'scientific sample', and for the experiments without the words 'scientific' sample, led to the same conclusion in both cases. There was on average an increase of 2 percentage points in all cases where the non-solicitation (not selling anything) argument was used. In other words, the overall effect of the nonsolicitation argument was comparable for surveys using further respondent selection and therefore using in addition the word scientific sample and for surveys that did not use the word scientific sample. Overall, the non-solicitation argument (not selling) appears to be far more important than the word 'scientific.'

The message 'I am not selling anything' has a positive effect on the willingness to cooperate in a telephone survey. People definitely react to the telephone introduction and they do listen to what is being said. The overall effect of 'I am not selling' was relatively small: 2 percentage points. However, it is very easy to implement, and cost effective. Another, more costly method to convey reassurance is an advance letter. Sending an advance letter in the I 970 s could have an effect of an increase in response of $7-9$ percentage points (Heberlein \& Baumgartner, I978). However, much depends on the content and length of the letter (Dillman, Gallegos, \& Frey, I976; Lynn, Turner, \& Smith, I997) and advance letters can even have a negative effect on response (for an overview, see Groves \& Couper, I998). Recent research in the UK (Lynn et al., I997) showed that the effect of a mell-pritten advance letter is currently around 3 percentage points, an effect that is comparable with the effect of the 'not selling' argument in the Dutch experiments. 
Furthermore, advance letters are only feasible when the postal addresses of the sample units are known, this excludes all telephone surveys using random digit dialing (RDD).

Summing up: as it is easy to implement and not costly, we strongly advise using a 'not selling anything'argument in the introduction of a telephone interview. We also advise using this non-solicitation argument as early as possible in the introduction.

\section{REFERENCES}

American Association for Public Opinion Research. (I998, June). Standard definitions: Final disposition of cases codes and outcome rates for RDD telephone surveys and inperson household surveys. Retrieved from http://www.aapor.org

American Statistical Association, Section on Survey Research Methods. (I999). More about telephone surveys. ASA Series What is a survey? (also on www.amstat.org/ sections/srms/).

Brennecke, S. (I998, April). Voorlichting over marktonderzoek blifft nodig [The necessity of correct information on market research]. Amsterdam: Memorandum 'Uw Mening Telt' [Memo Association Your Opinion Counts of the Netherlands Organisation for Market Research].

Campanelli, P., Sturgis, P., \& Purdon, S. (1997). Can you hear me knocking: An investigation in the impact of interviemers on survey response rates. London: SCPR (SCPR recently changed into Nat Cen).

Dillman, D. A., Gallegos, J. G., \& Frey, J. H. (I976). Reducing refusal rates for telephone interviews. Public Opinion Quarterly, 40, 66-78.

Dillman, D. A., Eltinge, J. L., Groves, R. M., \& Little, R. J. A. (2002). Perspectives on nonresponse. In R. M. Groves, D. A. Dillman. J. L. Eltinge, \& R. J. A. Little (Eds.), Survey nonresponse (pp.3-26). New York: Wiley.

Gonzenbach, W. J., \& Jablonski, P. (I993). The non-solicitation statement: A methodological consideration for survey introductions. Proceedings of the I993 AAPOR-conference. Retrieved January 22, 2004, from www.amstat.org (section on survey research methods).

Goold, S. (I997, May). 'Hello, I am calling from... 'Why respondents refuse to participate in telephone survey research. Paper presented at the Annual Conference of American Association for Public Opinion Research, Norfolk, Virginia.

Groves, R. M. (1992). Invited lecture on nonresponse for Statistics Netherlands. Voorburg, The Netherlands.

Groves, R. M., \& Couper, M. P. (I998). Nonresponse in household interviem surveys. New York: Wiley.

Groves, R. M., Biemer, P. P., Lyberg, L. E., Massey, J. T., Nicholls, W. L. II, \& Waksberg, J. (Eds.). (I988). Telephone survey methodology. New York: Wiley.

Heberlein, T. A., \& Baumgartner, R. M. (1978). Factors affecting response rates to mailed questionnaires: A quantitative analysis of the published literature. American Sociological Reviem, 43, 447-462.

Hox, J. (2002). Multilevel analysis:Techniques and applications. Mahwah, N.J.: Lawrence Erlbaum. 
Hox, J., \& Leeuw, E. D. de. (2002). The influence of interviewers' attitude and behaviour on household survey nonresponse: An international comparison. In R. M. Groves, D. A. Dillman. J. L. Eltinge, \& R. J. A. Little (Eds.), Survey nonresponse (pp. I03-120). New York: Wiley.

Hox, J., Leeuw, E. de, Snijkers, G. (I998). Fighting nonresponse in telephone interviews; successful interviewer tactics. $Z U M A$-Nachrichten, Spezial 4, I73-I85 (Special issue on Nonresponse in Survey Research, edited by A. Koch \& R. Porst).

Jaccard, J., Turrisi, R., \& Wan, C. K. (I990). Interaction effects in multiple regression. Newbury Park, CA: Sage

Leeuw, E. D. de. (I992). Data quality in mail, telephone, E face-to-face surveys. Amsterdam: TT-publikaties.

Leeuw, E. D. (I999). Preface: Special issue on survey nonresponse. Fournal of Official Statistics, 15 (2), I27-I28, also on www.jos.nu

Leeuw, E. D. de, \& Heer, W. de. (2002). Trends in household survey nonresponse: A longitudinal and international Comparison. In R. M. Groves, D. A. Dillman. J. L. Eltinge, \& R. J. A. Little (Eds.), Survey nonresponse (pp. 4I-54). New York: Wiley.

Leeuw, E. D. de, \& Zouwen, J. van der. (I988). Data quality in telephone and face-to-face surveys: A comparative meta-analysis. In R. M. Groves et al. (Eds.), Telephone survey methodology (pp. 283-299). New York: Wiley.

Lynn, P., Turner, R., \& Smith, P. (I997). The effect of complexity and tone of an advance letter on response to an interview survey. Survey Methods Centre Nemsletter, I7, I3-I7.

Maynard, D. W., \& Schaeffer, N. C. (1997). Keeping the gate: Declinations to the request to participate in a telephone survey interview. Sociological Methods $\mathbb{E}$ Research, 26(I), 34-79.

Nathan, G. (200I). Telesurvey methodologies for household surveys: A review and some thoughts for the future. Survey Methodology, 27(I), 7-3 I.

Pinkleton, B., Reagan, J., Aaronson, D., \& Ramo, E. (1994). Does 'I am not selling anything' increase response rates in telephone surveys? Proceedings of the I994 AAPOR conference. Retrieved January 22, 2004 from www.amstat.org (section on survey research methods).

Pondman, L. M. (1998). The influence of the interviemer on the refusal rate in telephone surveys. Deventer: Print Partners Ipskamp.

Robinson, J. (2003). Talking points for Do Not Call situation. Briefing memo CASRO. AAPORNET, i I october 2003 (Mark Schulman).

Schulman, M. (2003). Federal do-not-call registry exempts surveys. AAPOR News, retrieved July 29, 2003, from www.aapor.org

Smith, T. W. (2002). Developing nonresponse standards. In R. M. Groves, D. A. Dillman. J. L. Eltinge, \& R. J. A. Little (Eds.), Survey nonresponse (pp. 27-40). New York: Wiley.

Snijkers, G., Hox, J., de Leeuw, E. (I999). Interviewers' tactics for fighting survey nonresponse. Fournal of Official Statistics, I5(2), I 85-I 98 (also available at www.jos.nu).

Steenis, C. van. (1998, May). Bellen en gebeld worden: de feiten over telefoondruk [The facts about telephone pressure]. Amsterdam: Memorandum ' $U w$ Mening Telt'. 
[Memo Association Your Opinion Counts of the Netherlands Organisation for Market Research].

Tabachnick, B. G., \& Fidell, L. S. (200I). Using multivariate statistics. Boston: Allyn \& Bacon.

\section{BIOGRAPHICAL NOTES}

Edith D. de Leeuw, Ph.D., is associate professor of survey methodology at the Department of Methodology and Statistics at Utrecht University, the Netherlands. She also is director of MethodikA Amsterdam, consultants in methodology and statistics.

Joop J. Hox is a full professor of methodology at the Department of Methodology and Statistics at Utrecht University, the Netherlands. He specializes in survey methodology and the analysis of complex data, and is the author of Multilevel analysis: Techniques and applications, published by Lawrence Erlbaum.

Address correspondence to: Edith D. de Leeuw, Plantage Doklaan 40, NL-ror8 CN Amsterdam, The Netherlands, E-mail: edithl@xs4all.nl 